\title{
Nanoscale Phenomena Occurring during Pyrolysis of Salix viminalis Wood
}

\author{
Aleksandra W. Cyganiuk, ${ }^{1}$ Roman Klimkiewicz, ${ }^{2}$ Andrzej Olejniczak, ${ }^{1,3}$ \\ Anna Kucińska, ${ }^{1}$ and Jerzy P. Lukaszewicz ${ }^{1}$ \\ ${ }^{1}$ Faculty of Chemistry, Nicholas Copernicus University, Ulica Gagarina 11, 87-100 Torun, Poland \\ ${ }^{2}$ Institute of Low Temperature and Structure Research PAN, Ulica Okólna 2, 50-422 Wrocław, Poland \\ ${ }^{3}$ Flerov Laboratory of Nuclear Reactions, Joint Institute for Nuclear Research, Dubna 141980, Russia \\ Correspondence should be addressed to Jerzy P. Łukaszewicz; lukaszju@chem.uni.torun.pl
}

Received 13 November 2012; Accepted 13 March 2013

Academic Editor: Eric Guibal

Copyright (C) 2013 Aleksandra W. Cyganiuk et al. This is an open access article distributed under the Creative Commons Attribution License, which permits unrestricted use, distribution, and reproduction in any medium, provided the original work is properly cited.

Selective utilisation of unique properties of Salix viminalis wood enables preparation of materials of nanotechnologic properties. Thermal decomposition of lignin-cellulose organic matter results in the formation of a nanostructured porous carbon matrix (charcoal). Narrowed pore size distribution (PSD) in the subnanometer range allows to consider the charcoals as carbon molecular sieves (CMSs), which are capable of separating even chemically inert gases like neon, krypton, and nitrogen. High tolerance of Salix viminalis to heavy metal ions enables enriching living plant tissues with metal ions like lanthanum and manganese. Such ions may later form $\mathrm{LaMnO}_{3}$ with parallel transformation of plant tissues (organic matter) to carbon matrix using a heat treatment. In this way, one gets a hybrid material: a porous carbon matrix with uniformly suspended nanocrystallites of $\mathrm{LaMoO}_{3}$. The crystallites are in the catalytically active phase during the conversion of n-butanol to heptanone- 4 with high yield and selectivity.

\section{Introduction}

Thermal treatment of biomass (including wood) is usually seen as an ordinary technological process. However, in some cases, this process may trigger some phenomena, which, doubtlessly, should be regarded as a part of widely understood nanotechnology, because of the properties of materials obtained during pyrolysis. The current research is aimed to prove that the terms "nanomaterial," "nanotechnology," "nanoscale" should not be exclusively considered in relation to artificial, synthetic materials obtained by sophisticated methods. We demonstrate on selected examples that nanoscale effects are achievable by particular treatments of natural products and/or by utilisation of phenomena, which occur in living plants. The presented examples relate to the plant called Salix viminalis. Salix viminalis is one of so-called short-rotation coppice [1], planted as an easily renewable source of energy [2]. There are almost no other cases of utilising Salix viminalis beside those related with energy or phytoremediation [3] of water and soil. Apart from its proved high tolerance to heavy metal ions, Salix viminalis grows very fast in the mild climate zone, yielding hard wood in large quantities per a single hectare of crop area [4]. The high agricultural yield of Salix viminalis may considerably reduce the cost of products obtained from this material, provided that proposed methods are implemented in the industrial use.

1.1. Carbon Molecular Sieves. Carbon molecular sieve (CMS) is often defined as a carbonaceous material of a narrowed pore size distribution (PSD). CMS is widely used for gas separation [7], purification of mixtures, or in catalytic processes [8]. The phenomenon of selective adsorption depends not only on the size of pores, but also on other properties of CMS, such as electron properties. Unlike the other known molecular sieving mineral materials [9], CMSs possess adequate chemical $(\mathrm{pH})$ and thermal (in an inert atmosphere) stability and high hydrophobicity (if not chemically modified). 
Number of procedures and precursors for preparing CMSs have been proposed and developed since the discovery of molecular sieving effect of Saran char in the late 1940s [10]. More recently, highly ordered microporous and mesoporous materials, like zeolites or MCM silicas, have proved to be useful molecular sieves [11]. Silicas, as well as other inorganic materials, may also serve as a template for fabrication of carbon porous adsorbents of an adjustable pore structure [12]. However, the application of proposed methods in mass production of CMSs remains complicated as it involves several production steps and requires hazardous reagents. Further more, the product yield of the complex fabrication methods seems to be rather low, and therefore these methods are hardly applicable for industrial aims. Nearly the same shortcomings relate to fabrication of carbon nanotubes (CNTs). In general, after opening and fragmentation, CNTs might be regarded as a carbon-type adsorbent of narrowed pores size distribution (PSD) [13]. Such narrowed PSDs were mentioned also for active carbons, for preparation of which, initial materials were wood shells of walnut [14] or palm fruit [15]. It is claimed that such fabricated active carbons possess pore structure typical for molecular sieves, but in many cases, the determined PSD is not narrowed and therefore being far from the ideal one [16]. Regarding the mentioned applications of solids of narrowed PSD (including CMSs) and the shortcomings of some already discovered fabrication ways, one has to state that there is an obvious need for an inexpensive carbon-type adsorbent, in which pores are really uniform and their size is below $1 \mathrm{~nm}$, that is, somehow similar to size of molecules and atoms.

1.2. Formation of Metal Oxide Nanocrystallites in Carbon Matrix. Carbon-based materials are of a great interest in terms of their application in catalysis [17]. Such materials are catalysts, themselves but more frequently, they serve as a support for an actual catalytic phase, which often consists of metal/metal oxide clusters [18]. Laboratory practice exploits several routine ways to obtain carbon-based materials with metal/metal oxide clusters on the surface. The most classic methods are colloid deposition, electroplating, and ion exchange [19]. Currently available methods have not been applied for the deposition of clusters of perovskitetype oxides. Perovskite-type oxides are applied as oxygen reduction catalysts for fuel cells [20] or air-metal batteries [21]. Besides that, one of the newest trends in catalysis is the application of pure perovskite type oxides for the conversion of n-alcohols into aldehydes and/or ketones. Some catalysts are able to perform a secondary condensation of created aldehydes into ketones containing $2 n-1$ carbon atoms in the aliphatic chain. The " $n$ " mark denotes the number of $\mathrm{C}$ atoms in $n$-alcohol, which undergo the conversion. Lanthanum and manganese containing perovskite type oxides [22, 23] belong to the group of catalysts of potential catalytic activity towards ketonization of primary alcohols. Moreover, the application of carbon-type catalyst support enables utilisation of specific surfaces $[24,25]$ and catalytic $[26,27]$ properties of carbon. In addition, one may expect that some synergetic effects occur in the metal oxide-carbon $[28,29]$ system as often happens in case of other hybrid catalysts.

\section{Experimental}

2.1. Fabrication of Molecular Sieves. Harvested Salix viminalis rods are dried and grounded into shavings, about $1 \mathrm{~cm}$ long, then pyrolyzed. Carbonisation is carried out in two stages: (I) the preliminary stage $-1 \mathrm{~h}$ at $600^{\circ} \mathrm{C}$ for expelling some volatile species (II) the secondary stage $-1 \mathrm{~h}$ at arbitrarily chosen temperature $\left(600,700,800\right.$, and $\left.900^{\circ} \mathrm{C}\right)$ for expelling residual volatile fractions and the formation of nanopore-rich polycrystalline carbon matrix. Such carbons were denoted as SV. Two first numbers after the SV symbol like SV6171 describe primary carbonization (e.g., $6-600^{\circ} \mathrm{C}$, 1-1 hour), while the two remaining numbers describe secondary carbonization (e.g., 7-700 ${ }^{\circ} \mathrm{C}, 1-1$ hour). Additionally activated carbon sample were prepared as well. Raw Salix viminalis wood was saturated for $48 \mathrm{~h}$ with $\mathrm{ZnCl}_{2}$ solution $\left(4 \mathrm{~mole} / \mathrm{dm}^{3}\right)$. The saturation was followed by a standard twostep carbonization: preliminary $\left(1 \mathrm{~h}\right.$ at $\left.600^{\circ} \mathrm{C}\right)$ and secondary $\left(1 \mathrm{~h}\right.$ at $\left.600^{\circ} \mathrm{C}\right)$. Carbonized samples were intensively rinsed with water to eluate $\mathrm{ZnCl}_{2}$ which is leaving cavities (pores) in carbon matrix. Such activated carbon was denoted as DSV.

2.2. Fabrication of Hybrid $\mathrm{LaMnO}_{3} /$ Carbon Catalysts. Recently, one of us proposed [30] a novel way of fabricating hybrid carbon-based metal oxide-containing materials. The novelty of the method consists in the exploitation of natural phenomenon of metal ion transportation in living plants. Metal ions, after introduction to transport-responsible tissues in a living plant, are transported to almost every cell, since Salix viminalis is highly tolerant to the presence of metal ions (including heavy metals) in its body. Freshly cut stems of Salix viminalis were immersed (vertical alignment) in a water solution containing equimolar quantities of $\mathrm{La}\left(\mathrm{NO}_{3}\right)_{3}$ and $\mathrm{Mn}\left(\mathrm{NO}_{3}\right)_{2}$ (example concentrations: $0.001 \mathrm{M}, 0.01 \mathrm{M}$, and $0.1 \mathrm{M})$. The stems retained the ability of intensive capillary suction resulting in a gradual rise of the solution along the stems. After saturation with $\mathrm{La}^{3+}$ and $\mathrm{Mn}^{2+}$ ions, the stems were dried, diminished, and carbonized $\left(600-800^{\circ} \mathrm{C}\right.$, a twostep procedure) in an inert gas atmosphere $\left(\mathrm{N}_{2}\right)$. First, the metal ion saturated wood was carbonized for $1 \mathrm{~h}$ at $600^{\circ} \mathrm{C}$ $\left(\mathrm{N}_{2}\right.$ atmosphere) in order to remove volatile species and to transform the wood (lignin-cellulose) matrix into carbonbased matrix. Next, heat treatment $\left(1 \mathrm{~h}, \mathrm{~N}_{2}\right.$ flow) at the temperature of $800^{\circ} \mathrm{C}$ enabled preserving developed pore structure, and, what is the most important, it enabled the transformation of introduced metal ions into appropriate metal oxides.

2.3. Determining a Pore Structure. The pore structure and specific surface areas were determined using a widely accepted method, which utilises the phenomenon of low temperature adsorption of chemically neutral gases [31]. Authors applied nitrogen as an inert adsorptive. Nitrogen adsorption isotherms were recorded at the temperature of liquid nitrogen $\left(-196^{\circ} \mathrm{C}\right)$ using Micromeritics ASAP 2010. The standard 
TABLE 1: Weight content of main elements in selected carbonised plants. Results obtained using the EDS/EDX method at particular spots on the surface of carbon samples. Results selected according to the highest carbon content ever recorded for a particular carbon type.

\begin{tabular}{|c|c|c|c|c|c|c|}
\hline \multirow{2}{*}{ Carbonized plant } & \multicolumn{6}{|c|}{ Element content $(\% \mathrm{w} / \mathrm{w})$} \\
\hline & $\mathrm{C}$ & $\mathrm{O}$ & $\mathrm{Ca}$ & $\mathrm{Mg}$ & $\mathrm{K}$ & Residual elements \\
\hline $\begin{array}{l}\text { Basket willow (wood) } \\
\text { Salix viminalis }\end{array}$ & 81.4 & 15.8 & 0.7 & - & 1.6 & 0.5 \\
\hline $\begin{array}{l}\text { Elder (wood) } \\
\text { Sambucus nigra }\end{array}$ & 80.5 & 16.9 & 0.4 & 0.3 & 1.6 & 0.3 \\
\hline $\begin{array}{l}\text { Brittle willow (wood) } \\
\text { Salix fragilis }\end{array}$ & 81.9 & 16.7 & - & 0.2 & 1.1 & 0.1 \\
\hline $\begin{array}{l}\text { Common pine (wood) } \\
\text { Pinus sylvestris }\end{array}$ & 85.6 & 13.5 & 0.5 & 0.1 & 0.3 & - \\
\hline $\begin{array}{l}\text { Pistachio tree (fruit shells) } \\
\text { Pistacia vera }\end{array}$ & 79.0 & 17.4 & - & - & 1.9 & 1.7 \\
\hline $\begin{array}{l}\text { Plum tree (fruit stone) } \\
\text { Prunus domestica }\end{array}$ & 86.3 & 13.2 & - & - & 0.5 & - \\
\hline $\begin{array}{l}\text { Norway maple (wood) } \\
\text { Acer platanoides }\end{array}$ & 84.2 & 14.3 & 0.4 & 0.3 & 0.6 & 0.2 \\
\hline $\begin{array}{l}\text { Black poplar (wood) } \\
\text { Populus nigra }\end{array}$ & 79.5 & 19.0 & - & 0.5 & 0.9 & 0.1 \\
\hline $\begin{array}{l}\text { Common birch (wood) } \\
\text { Betula pendula }\end{array}$ & 84.8 & 14.3 & - & 0.2 & 0.7 & - \\
\hline
\end{tabular}

software provided by the manufacturer of ASAP 2010 was employed for the regression of primary obtained adsorption data (nitrogen adsorption versus relative partial pressure of the adsorptive). Two regression models were applied: BET [32] for the calculation of specific surface area of carbons and $\mathrm{H}-\mathrm{K}$ method [33] for the calculation of pore size distribution (PSD) [34]. No changes were introduced to the standard calculation procedures offered by the commercial software [35]. All tested carbon samples were degassed in vacuum $(0.133 \mathrm{~Pa})$ at elevated temperature $\left(250^{\circ} \mathrm{C}\right)$ for extended time (3 hours) before nitrogen adsorption measurements.

2.4. Gas Mixture Separation. Chromatographic tests were performed using a gas chromatograph Schimadzu GC-14B, supplied with a TCD detector kept at constant temperature of $110^{\circ} \mathrm{C}$. Carrier gas (helium) was fed with 10, 15, 20, 25, 30,40 , and $50 \mathrm{~mL} / \mathrm{min}$ intensities. The flow rate value was set, depending on the results of van Deemter optimisation procedure, performed prior to the separation tests. A glass chromatographic loop was $2.5 \mathrm{~m}$ long and its inner diameter was $2.6 \mathrm{~mm}$. The separation tests were performed at several temperatures $\left(70,60,50,40\right.$, and $\left.30^{\circ} \mathrm{C}\right)$ and consisted in recording of chromatograms for injected samples (pure gases, 2-component and 3-component mixtures). The chromatograms let us determine retention times and separation factors.

2.5. Catalytic Tests. The conversion of $\mathrm{n}$-butanol was applied as a testing reaction. All runs were performed at the atmospheric pressure without addition of any carrier gases. A vertical quartz reactor of $10 \mathrm{~mm}$ inside diameter with a fixed bed containing $4 \mathrm{~mL}$ ( $0.77 \mathrm{~g}$ only) of catalyst of $0.6-1.2 \mathrm{~mm}$ particle size was used. The reactor was placed in a vertical pipe furnace. The tests were initiated at $300^{\circ} \mathrm{C}$ and conducted in a function of increasing temperature up to $480^{\circ} \mathrm{C}$. Alcohol was introduced to the preheating zone at the top of the reactor, using a syringe infusion micropump at the variable flow rate of 1 to $3 \mathrm{~mL} / \mathrm{h}$. The products were analysed using gas chromatography.

2.6. Other. The morphology of the samples was investigated by means of an electron microscope (LEO 1430 VP, Electron Microscopy Ltd.) which was supplied with two detectors for secondary electrons (SEs), back-scattered electrons (BSEs), and X-ray elemental analyser (EDX). Such experimental setup enabled authors to determine the elemental composition of specific areas and display all details on scanning electron images (HRTEM (JEOL, JEM 2000 EX)). Apart from SEM observations, other investigations were performed as well.

\section{Results and Discussion}

The obtained carbon consists mainly of $\mathrm{C}, \mathrm{O}, \mathrm{N}$, and $\mathrm{H}$ atoms (Table 1). Table 1 additionally presents original data obtained by the authors on the elemental composition of carbons produced by pyrolysis of other nonconventional kinds of wood. The results obtained for Salix viminalis are typical for wood originated chars which in ca. 80\% (atomic content) consists of carbon. Such chars are also characteristic by high content of oxygen (ca. 15\%) which influences severely the selection of a test gas for PSD determination that is practically excluding polar species like $\mathrm{CO}_{2}$.

3.1. Formation of Uniform Nanopores in Carbon Matrix Obtained by Carbonisation of S. viminalis Wood. Figure 1 


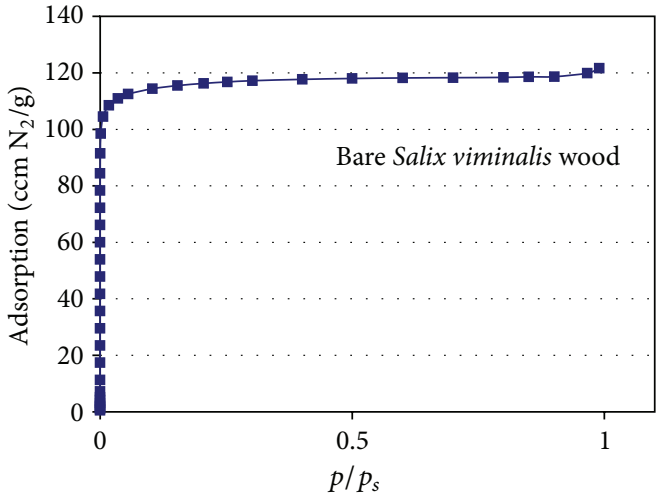

(a)

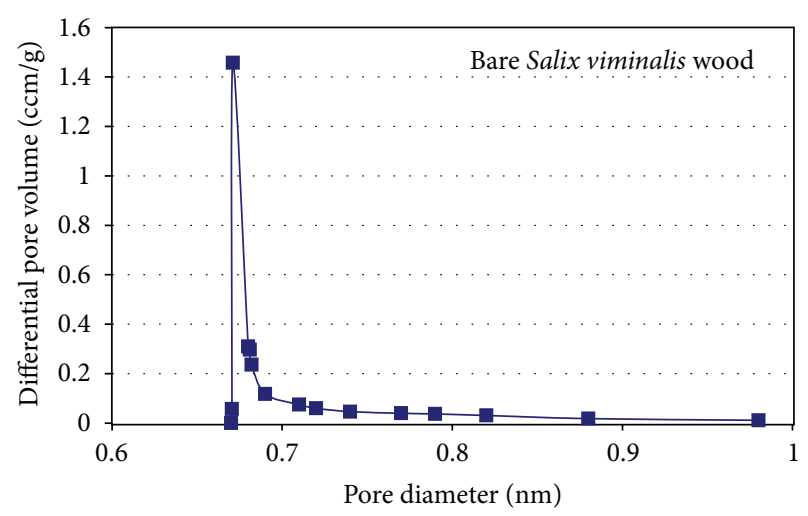

(b)

FIGURE 1: (a) Nitrogen adsorption isotherms recorded at $-196^{\circ} \mathrm{C}$ for a virgin carbon sample SV6161 fabricated from Salix viminalis wood. (b) PSD functions determined from corresponding nitrogen adsorption isotherms.

depicts a nitrogen adsorption isotherm, recorded at $-196^{\circ} \mathrm{C}$ for investigated carbonized Salix viminalis wood pieces. The determined nitrogen adsorption isotherms for such carbons were of the type I of the IUPAC classification, with the plateau reached for very low values of relative pressures $\left(p / p_{s}\right)$ of the adsorbate. Such shape of isotherms allows to assume that the adsorbent is potentially a strictly microporous (nanoporous in fact) solid material; however, this assumption has to be proved by additional analyses. Regression of the adsorption data [33] pointed out very narrowed PSD which was the main aim of the performed research: inexpensive fabrication of nanosized molecular-sieve type carbons. The effective diameter of pores is definitely below $1 \mathrm{~nm}$, what makes such produced carbons a unique and promising adsorbent for gas separation aims [36] (see later chapters). Beside gas separation, gas storage may be regarded as another possible field of application for these carbons. In the case of simple carbonization of Salix viminalis wood, specific surface area of raw carbons reaches the values of $300-400 \mathrm{~m}^{2} / g$. Structure of investigated CMSs is depicted in the HRTEM micrograph (Figure 2). The carbon phase consists of numerous ordered domains, which are randomly oriented graphite crystallites. Similar concept of the structure of pyrolytic carbons is widely presented in the literature in forms of idealized diagrams. Differently oriented graphene sheets built slit-like cavities, which are considered as typical pores in partly graphitized pyrolytic carbons.

Just obtained raw pyrolytic carbons and/or organic precursors for their fabrication can be subjected to several procedures leading to the development of the total micropore volume and specific surface area $\left(\mathrm{H}_{3} \mathrm{PO}_{4}\right.$ and $\mathrm{CO}_{2}$ activation procedures). The activation treatments increase the total nitrogen uptake at $p / p_{s}$ above 0.95 , but the shape of the nitrogen adsorption isotherm and PSD remained unchanged. The same effect, that is, qualitatively unchanged PSD, has been found as a result of fabrication procedures performed at different carbonization temperatures. Up-to-date obtained results enable us to state that most of the mentioned activation methods lift the value of specific surface area above $1100 \mathrm{~m}^{2} / \mathrm{g}$. In general, activation procedures yielded carbons of a well-developed surface area and micropore volume. However, the previously mentioned very narrow PSD, observed for nonactivated carbons, was preserved in case of activated carbons.

In general, the PSD determination is a complex analysis, with results highly dependant on the kind of adsorptive, that is, a gas being physically adsorbed by the solid under investigation. The regression model of adsorption data plays a crucial role as well. Usually, $\mathrm{Ar}, \mathrm{N}_{2}$, and $\mathrm{CO}_{2}$ are applied for this purpose. According to some studies [37], the usefulness of $\mathrm{N}_{2}$ is limited due to its slow diffusion into micropores (linear diameter below $2 \mathrm{~nm}$ ) at $-196^{\circ} \mathrm{C}$. Physical adsorption of $\mathrm{CO}_{2}$ (at $0^{\circ} \mathrm{C}$ or $25^{\circ} \mathrm{C}$ ) was proposed as new standard procedure for PSD determination [37] regardless of some evidently negative properties of $\mathrm{CO}_{2}$.

(i) $\mathrm{CO}_{2}$ is not chemically inert, particularly at room temperature (evident acidic properties which may lead to specific reaction with base centres on the surface).

(ii) $\mathrm{CO}_{2}$ molecule is not a dipole but high negative charge is cumulated on both $\mathrm{O}$ atoms (specific molecular interactions may be expected).

(iii) $\mathrm{CO}_{2}$ has a specific longitude shape ("long" 3-atom linear molecule may cause orientation issues).

Recently, some research suggested inapplicability of $\mathrm{N}_{2}$ preferring $\mathrm{CO}_{2}$, in contrast to other studies proving comparativeness of $\mathrm{Ar}, \mathrm{N}_{2}$, and $\mathrm{CO}_{2}$ results in terms of PSD determination [38]. Theoretical simulation of $\mathrm{Ar}, \mathrm{N}_{2}$, and $\mathrm{CO}_{2}$ adsorption [39-41] in a model pore structure proved particular usefulness of $\mathrm{Ar}$ as a probe gas. Low temperature adsorption of $\mathrm{N}_{2}$ was let to determine PSDs only slightly differing from Ar-based PSDs. According to the studies, applicability of $\mathrm{CO}_{2}$ in case of carbons of high content of heteroatoms (particularly oxygen) seems to be limited in case of the carbon surface with implanted surface functional groups, since numerically generated $\mathrm{CO}_{2}$-based PSDs suffered from the presence of false pores (nonexisting in the assumed pore structure). Thus, despite some objections, $\mathrm{N}_{2}$ adsorption at 


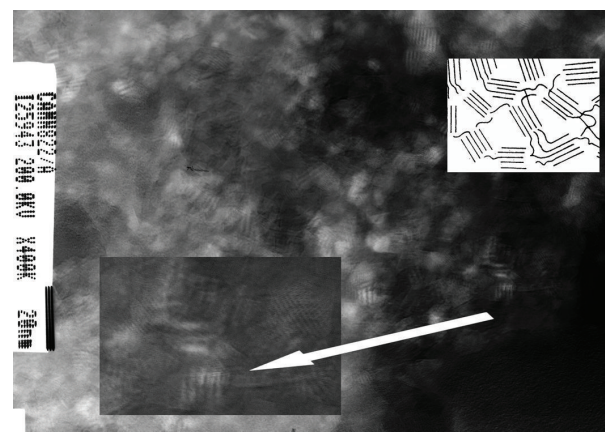

FIGURE 2: Structure of virgin carbon obtained from Salix viminalis wood SV6161 studied by HRTEM: randomly oriented graphite crystallites suspended in amorphous carbon phase. Historically, first theoretical model of carbon was elaborated in early fifties in 20th century [5]: inserted in the right upper corner. A novel model has been proposed recently [6].

$-196^{\circ} \mathrm{C}$ may still serve as a standard experiment, providing reliable qualitative information on the run of PSD curves for real carbons, particularly those obtained by carbonisation of wood (high contents of polar surface oxygen and nitrogen groups).

3.2. Separation of Inert Gases by Means of Nanoporous CMS. In the light of the perveious statements, the obtained Salix viminalis-originated carbons possess molecular sievetype pore structure, which is dominated by ultra-fine pores of size placed in the subnanometric range. Such discrete pore size distribution should be proved in practice despite determination of PSD functions presented earlier. Authors proposed a gas mixture separation $\left(\mathrm{N}_{2}\right.$ and $\left.\mathrm{Kr}\right)$ in dynamic conditions. The gases differ from each other in terms of symmetry, $\mathrm{Kr}$ is supposed to be a sphere (no dipole or quadrupole moment), while $\mathrm{N}_{2}$ is a linear molecule with differentiated size if measured along or perpendicular to the nitrogen-nitrogen triple bond. In some circumstances, quadrupole moment of $\mathrm{N}_{2}$ molecule may play important role. The literature quotes similar kinetic diameter for nitrogen and krypton $\left(\mathrm{N}_{2}-0.364 \mathrm{~nm}\right.$ and $\left.\mathrm{Kr}-0.360 \mathrm{~nm}\right)$ [42], but some resources [43] suggest other diameters of $\mathrm{N}_{2}$ molecule, depending on the molecule orientation, that is, whether measured perpendicular to $\mathrm{N}-\mathrm{N}$ bond $(0.300 \mathrm{~nm})$. Separation of the slightly differing (geometrically) gases might be effective, provided an adsorbent contains pores of a size comparable to dimensions of the molecules under consideration. In practice, high content of nanopores (diameter below $1 \mathrm{~nm}$ ) provides effective gas separation as in pressure swing adsorption (PSA) air separation method. In our study, a mixture of $\mathrm{Kr}$ and $\mathrm{N}_{2}$ was injected into a chromatographic column packed with nanosized CMS, originated from Salix viminalis wood. Table 2 contains retention times, while Table 3 presents the data from Table 2 recalculated to separation factors for both gases.

Retention times for $\mathrm{Kr}$ are, in general, very long (minimum 8 minutes) at all investigated temperatures $\left(30-70^{\circ} \mathrm{C}\right)$ or even longer than 20 minutes. Krypton atoms are retained, on average three times longer in the column filled with nanosized CMSs obtained from Salix viminalis. This may result from comparable dimensions of potential energy "well" in nanopores (calculated linear dimension below $1 \mathrm{~nm}$ ) and the size of $\mathrm{Kr}$ atoms which leads to a relatively durable entrapment of the atoms in pores. Retention times in the same experimental conditions for $\mathrm{N}_{2}$ are considerably shorter, ranging from 3 to 4.5 minutes and only slightly depending on the temperature of measurement conditions. The effect of shorter retention may be explained by several factors, one of which is a nonspherical shape of $\mathrm{N}_{2}$ molecules. This conclusion seems to be probable since isosteric heat of adsorption $Q_{\mathrm{ST}}$ on microporous carbons (carbon molecular sieves) is very nearly equal for $\mathrm{N}_{2}(23.9 \pm 0.8 \mathrm{~kJ} / \mathrm{mol})$ and for $\mathrm{Kr}(22.9 \pm 0.3 \mathrm{~kJ} / \mathrm{mol})$ [44]. Thus, natural tendency to prefer exothermic processes does apply to this case. Extensive studies [44] on the mechanism of adsorption on CMS led to the conclusion that two basic factors are essential for the overall process: (1) entering the pore (based on relent potential barrier at the pore entrance) and (2) diffusion along the pore (based on spot-to-spot hopping mechanism). However, author stated [44] that the rate-limiting process was the entry through the pore aperture, which may be considered as a "geometric factor," being in fact a certain potential barrier at the entrance. Both factors (1) and (2) are somehow summarized in the observed adsorption rate. If entering pores is a key factor as suggested and proven in several studies, even small differences in size and shape of adsorbing molecules highly influence adsorption-desorption kinetics. Such phenomenon is utilised in air separation for $\mathrm{N}_{2}$ and $\mathrm{O}_{2}$. The size of both biatomic molecules slightly differs (kinetic diameters: $\mathrm{N}_{2}-0.364 \mathrm{~nm}$ and $\mathrm{O}_{2}-0.346 \mathrm{~nm}$ ), but oxygen desorption kinetics is faster than of nitrogen, and oxygen is released prior to nitrogen from pressurized chambers in the PSA method for air separation [45]. That enables efficient separation of the two basic components of air, which is commonly used in industry, over active carbon bed, provided its porosity is properly tailored (sub-nanoscale pores dominate). Moreover, adsorption/desorption activation energies can also favour faster adsorption/desorption of oxygen. Studies [46] on the adsorption of oxygen and nitrogen on CMSs proved differences in adsorption/desorption activation energies. The activation energy for nitrogen adsorption was (at $30-70^{\circ} \mathrm{C}$ ) ca. $43 \mathrm{~kJ} / \mathrm{mol}$, while the corresponding value for oxygen was $\left(0-40^{\circ} \mathrm{C}\right) \mathrm{ca} .35 \mathrm{~kJ} / \mathrm{mol}$. That resulted in a relatively fast adsorption/desorption of oxygen if compared to nitrogen.

We assume that a corresponding situation occurs in our study, causing fast adsorption/desorption of nitrogen (short retention times) and slowing the processes down in the case of krypton (long retention times). Thus, smaller molecules, like specifically oriented $\mathrm{N}_{2}$, may relatively easily pass through the centre of pore entry (where the height of barriers is the lowest), even having low kinetic energy.

Weak dependency of nitrogen retention times on temperature if compared to $\mathrm{Kr}$ was observed. Bigger $\mathrm{Kr}$ atoms must possess high kinetic energy in order to overcome repulsing potential barrier at the pore entry. Therefore, the observed Kr retention times are more temperature dependent. 
TABLE 2: Retention times recorded for $\mathrm{N}_{2}$ and $\mathrm{Kr}$ separated on example carbon molecular sieves originated from Salix viminalis wood.

\begin{tabular}{|c|c|c|c|c|c|c|c|c|c|c|}
\hline \multirow{3}{*}{ Gas } & \multicolumn{10}{|c|}{$T\left({ }^{\circ} \mathrm{C}\right)$} \\
\hline & \multicolumn{2}{|c|}{70} & \multicolumn{2}{|c|}{60} & \multicolumn{2}{|c|}{50} & \multicolumn{2}{|c|}{40} & \multicolumn{2}{|c|}{30} \\
\hline & $t_{r}$ & $\pm \Delta t_{r}$ & $t_{r}$ & $\pm \Delta t_{r}$ & $t_{r}$ & $\pm \Delta t_{r}$ & $t_{r}$ & $\pm \Delta t_{r}$ & $t_{r}$ & $\pm \Delta t_{r}$ \\
\hline & \multicolumn{10}{|c|}{ Carbon SV6163 } \\
\hline $\mathrm{Kr}$ & 1544 & 41.7 & 1770 & 23.2 & 2128 & 77.3 & 2654 & 47.4 & 3393 & 176.2 \\
\hline \multirow[t]{2}{*}{$\mathrm{N}_{2}$} & 487 & 1.5 & 526 & 1.0 & 567 & 1.8 & 641 & 8.0 & 737 & 1.0 \\
\hline & \multicolumn{10}{|c|}{ Carbon DSV6161 } \\
\hline $\mathrm{Kr}$ & 886 & 7.8 & 1039 & 4.5 & 1285 & 64.5 & 1507 & 29.9 & 1758 & 15.3 \\
\hline $\mathrm{N}_{2}$ & 386 & 2.7 & 412 & 2.7 & 459 & 1.6 & 504 & 0.8 & 551 & 4.6 \\
\hline
\end{tabular}

$t_{r}$ : retention time $(\mathrm{s})$.

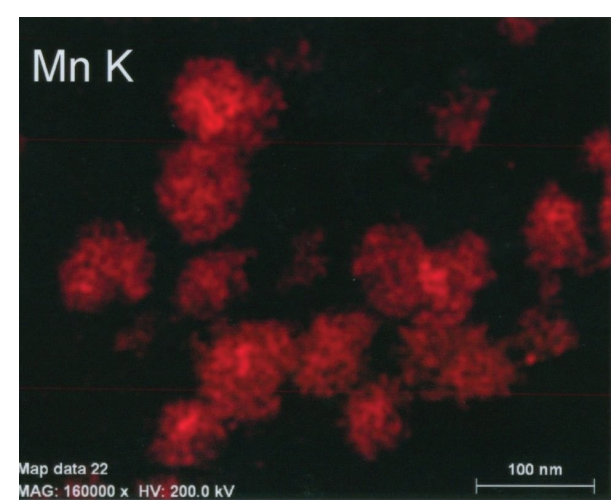

(a)

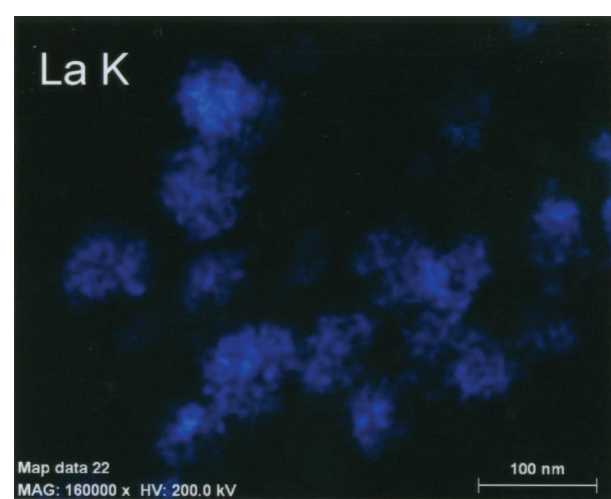

(b)

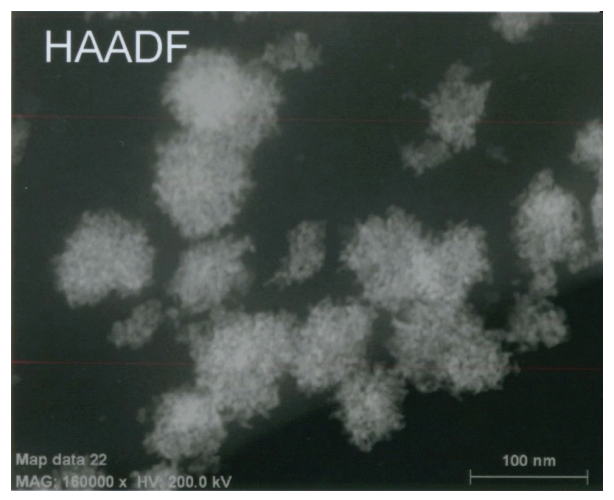

(c)

FIGURE 3: SEM-EDS/EDX images presenting common occurrence of La and Mn atoms in carbon sample obtained from Salix viminalis wood saturated with $\mathrm{La}^{3+}$ and $\mathrm{Mn}^{2+}$ ions prior to carbonization.

3.3. Formation of Nanoclusters of Complex Oxide $\left(\mathrm{LaMnO}_{3}\right.$ Perovskite) in Carbon Matrix, Obtained by Carbonization of S. viminalis Wood: Fabrication of a Catalyst for Ketonization of $n$-Alcohols. Figure 3 presents a series of HR-TEM images recorded for a carbon, obtained by carbonization of Salix viminalis wood, previously enriched (saturated) with La and $\mathrm{Mn}$ atoms. Short carbonisation times did not lead to the formation of $\mathrm{LaMnO}_{3}$, crystals [47] in the carbon amorphous matrix. However, EDS/EDX maps show common occurrence of La and Mn atoms in particulars spots in the carbon matrix. Important changes are visible for samples, subjected to a heat treatment for 22 hours. This observation is consistent with other studies on the synthesis of pure $\mathrm{LaMnO}_{3}$ [47] and formerly presented XRD diffraction studies, in which diffraction spectra were in perfect agreement with XRD spectrum recorded for $\mathrm{LaMnO}_{3.15}$ [48].

Figure 4 shows that the extension of heat treatment time (22 hours) leads to the formation of crystalline inorganic nanoclusters inserted into carbon matrix, with apparent results of graphitization. Past XRD and XPS investigations [49] doubtlessly proved that clusters consist of $\mathrm{LaMnO}_{3}$ with no significant excess of other lanthanum and manganese derivatives like single metal oxides $\left(\mathrm{La}_{2} \mathrm{O}_{3}, \mathrm{Mn}_{2} \mathrm{O}_{3}\right.$, and/or $\mathrm{MnO}_{2}$ ). Thus, there is a real background to state that 


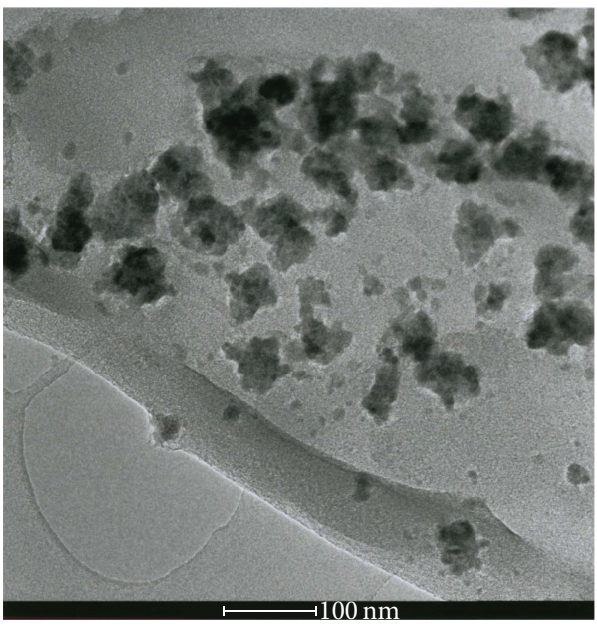

(a)

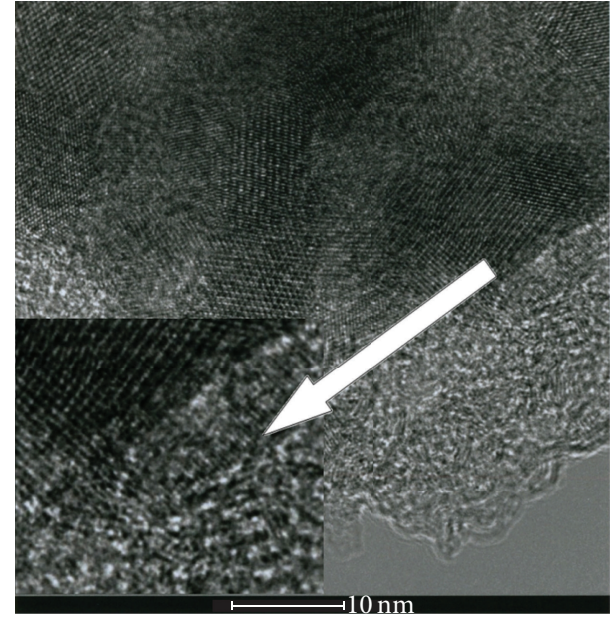

(b)

FIGURE 4: HRTEM image presenting interface among $\mathrm{LaMnO}_{3}$ crystallite and partly graphitized carbon matrix.

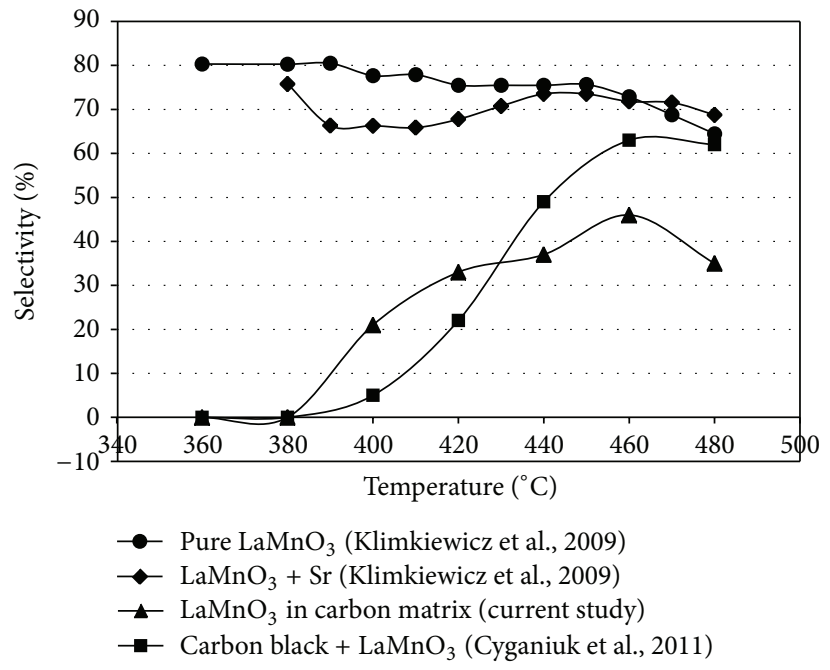

(a)

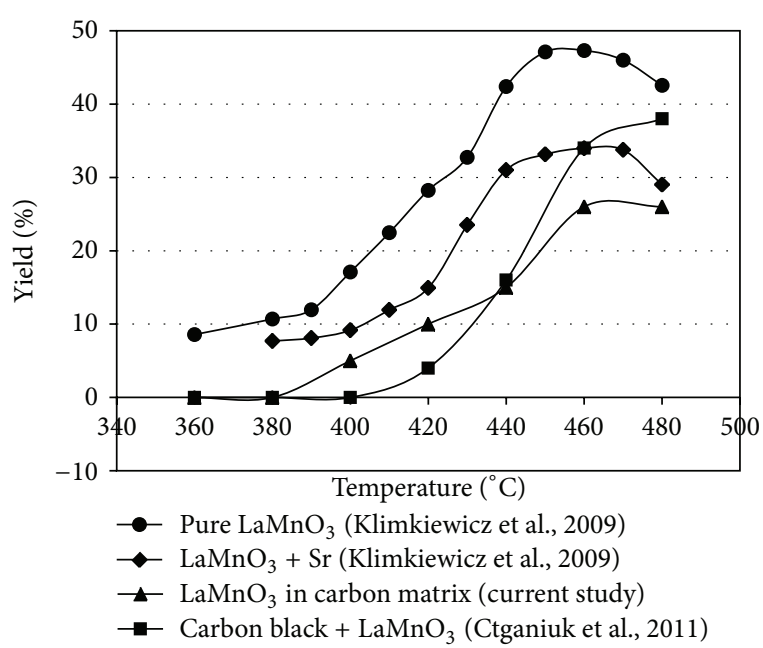

(b)

FIGURE 5: Selectivity (a) and yield (b) in the catalytic conversion of n-butanol to heptanone-4 over different catalyst containing $\mathrm{LaMnO}_{3}$.

TABLE 3: Retention coefficients determined for $\mathrm{N}_{2}$ and $\mathrm{Kr}$, separated on example Salix viminalis wood originated carbons (carrier gas flow $15 \mathrm{~mL} / \mathrm{min}$ ).

\begin{tabular}{lcccc}
\hline & \multicolumn{4}{c}{ Gas mixture $\mathrm{Kr}+\mathrm{N}_{2}$} \\
$T\left({ }^{\circ} \mathrm{C}\right)$ & $R_{s}$ & $\pm \Delta R_{s}$ & $R_{s}$ & $\pm \Delta R_{s}$ \\
\hline 70 & 4.90 & 0.34 & 7.91 & 0.68 \\
60 & 4.88 & 0.23 & 9.00 & 0.84 \\
50 & 5.04 & 0.73 & 9.23 & 2.61 \\
40 & 4.91 & 0.67 & 10.56 & 1.26 \\
30 & 6.23 & 1.60 & 10.78 & 0.99 \\
\hline
\end{tabular}

during carbonisation of mixed metal ions in plant tissues, even complex metal oxides, like perovskite-type oxides, may participate at synthesis, in the form of nanocrystallites, whose diameter is ca. $10 \mathrm{~nm}$. Such high dispersion of $\mathrm{LaMnO}_{3}$ nanocrystallites results from uniform distribution of $\mathrm{La}^{3+}$ and $\mathrm{Mn}^{2+}$ ions in the living plant cells. During carbonisation, an organic matter transforms into a porous carbon matrix, while the metal cations react, yielding perovskite-type oxide crystallites, separated by layers of carbon.

Despite the performed impregnation of raw wood with metal cations $\left(\mathrm{La}^{3+}\right.$ and $\mathrm{Mn}^{2+}$ ), the obtained hybrid material $\left(\mathrm{LaMnO}_{3} /\right.$ carbon) is still porous and resembles a perfect molecular sieve. The run of PSD functions for $\mathrm{LaMnO}_{3} /$ carbon samples is as narrow as for raw carbons, which do not contain inorganic phase. However, intensive enrichment of $S$. viminalis wood with $\mathrm{La}$ and $\mathrm{Mn}$ resulted in reduced specific surface area from $404 \mathrm{~m}^{2} / \mathrm{g}$ (sample D0.01 LaMn 61822) to $235 \mathrm{~m}^{2} / \mathrm{g}$ (sample D0.1 LaMn 61822) upon 
increasing concentration of impregnating solutions from $0.01 \mathrm{M}$ to $0.10 \mathrm{M}$.

Some results of catalytic tests consisting in conversion of n-butanol are presented in Figure 5. One may state that the tested perovskite-type oxide $\mathrm{LaMnO}_{3}$ in the form of nanocrystallites is an active catalyst, at higher temperatures but also for the formation of ketones (heptanone-4). In the same experimental conditions, pure carbon samples, that is, without $\mathrm{LaMnO}_{3}$, are not catalytically active. Thus, the noticed catalytic activity results from the presence of real catalysts- $\mathrm{LaMnO}_{3}$ nanocrystals. The material is less active (Figure 5) than pure $\mathrm{LaMnO}_{3}$; however, the catalysts phase content is extremely low (ca. $0.30 \%$ atomic content of La and Mn atoms proved by XPS measurements). The tested catalysts show activity (yield and selectivity) comparable to other hybrid catalysts (carbon black- $\mathrm{LaMnO}_{3}$ ) containing $10 \%$ of the perovskite-type oxide (by weight). Both key catalytic parameters, that is, selectivity and yield, are satisfactory at this stage of research. Even in extreme conditions, liquefied products were colourless without any yellowish shade. The shade would be a sign of undesired products like some resins and tars products.

\section{Conclusions}

Salix viminalis seems to be an ordinary woody plant, but it possesses unique features like organic tissues transforming into a durable strictly porous carbon matrix, resembling a perfect molecular sieve (very narrow PSD function). Its second useful feature is a high tolerance to heavy metals, what enables saturation of plants' living tissues with heavy metal ions. Carbonisation of metal saturated tissues leads to the formation of metal oxide (even complex oxides like $\mathrm{LaMnO}_{3}$ ) crystallites suspended in the carbon matrix. Both pore size in carbon matrix and the size of metal oxide crystallites enable accounting such obtained materials to the group of nanomaterials: nanoporous carbon adsorbent and hybrid $\mathrm{LaMnO}_{3}$ (nano-dispersed)/carbon catalyst. Sieving properties were proved by fast and efficient separation of $\mathrm{N}_{2} / \mathrm{Kr}$ gas mixture over the nanoporous carbon adsorbent despite minimal differences in the dimensions of nitrogen molecule and krypton atom. The presence of highly dispersed $\mathrm{LaMnO}_{3}$ phase on the carbon-type support enabled effective conversion of n-butanol into heptanone-4, despite the minute content the catalytically active phase.

\section{Nomenclature}

PSD:

CMS:

CNT:

Pore size distribution function

Carbon molecular sieve

BET Surface Area: Specific surface area determined by BET method $\left(\mathrm{m}^{2} / \mathrm{g}\right)$

HRTEM: $\quad$ High resolution transmission electron microscopy

SEM: EDS/EDX:
Energy-dispersive X-ray spectroscopy (or XEDS).

\section{References}

[1] L. Christersson and L. Sennerby-Forsse, "The swedish programme for intensive shortrotation forests," Biomass and Bioenergy, vol. 6, no. 1-2, pp. 145-149, 1994.

[2] K. Stanczyk and M. Ludwik, "Energy forests. Energy Forest Development on Areas in Central-Eastern Europe, where the Agricultural Production is Uneconomical," Central Mining Institute, Katowice, Poland, 2003.

[3] M. Labrecque, T. I. Teodorescu, and S. Daigle, "Biomass productivity and wood energy of Salix species after 2 years growth in SRIC fertilized with wastewater sludge," Biomass and Bioenergy, vol. 12, no. 6, pp. 409-417, 1997.

[4] W. Sobczyk, "Plonowanie wierzby wiciowej w świetle badań naukowych," Polityka Energetyczna, vol. 10, no. 2, pp. 547-555, 2007.

[5] R. E. Franklin, "Crystallite growth in graphitizing and nongraphitizing carbons," Proceedings of the Royal Society A, vol. 209, pp. 196-218, 1951.

[6] P. J. F. Harris, "Fullerene-like models for microporous carbon," Journal of Materials Science, vol. 48, no. 2, pp. 565-577, 2013.

[7] A. I. Shirley and N. O. Lemcoff, "Air separation by carbon molecular sieves," Adsorption, vol. 8, no. 2, pp. 147-155, 2002.

[8] I. I. Ivanova, A. S. Kuznetsov, V. V. Yuschenko, and E. E. Knyazeva, "Design of composite micro/mesoporous molecular sieve catalysts," Pure and Applied Chemistry, vol. 76, no. 9, pp. 1647-1658, 2004.

[9] A. Corma, "From microporous to mesoporous molecular sieve materials and their use in catalysis," Chemical Reviews, vol. 97, no. 6, pp. 2373-2419, 1997.

[10] P. H. Emmett, "Adsorption and pore-size measurements on charcoals and whetlerites," Chemical Reviews, vol. 43, no. 1, pp. 69-148, 1948.

[11] V. Antochshuk and M. Jaroniec, "Simultaneous modification of mesopores and extraction of template molecules from MCM-41 with trialkylchlorosilanes," Chemical Communications, no. 23, pp. 2373-2374, 1999.

[12] Z. G. Shi, Y. Q. Feng, L. Xu, S. L. Da, and M. Zhang, "A template method to control the shape and porosity of carbon materials," Carbon, vol. 42, no. 8-9, pp. 1677-1682, 2004.

[13] Q. Wang, S. R. Challa, D. S. Sholl, and J. K. Johnson, "Quantum sieving in carbon nanotubes and zeolites," Physical Review Letters, vol. 82, no. 5, pp. 956-959, 1999.

[14] Z. Hu and E. F. Vansant, "Carbon molecular sieves produced from walnut shell," Carbon, vol. 33, no. 5, pp. 561-567, 1995.

[15] J. S. Tan and F. N. Ani, "Carbon molecular sieves produced from oil palm shell for air separation," Separation and Purification Technology, vol. 35, no. 1, pp. 47-54, 2004.

[16] S. Manocha, "Porous carbons," Sadhana, vol. 28, no. 1-2, pp. 335348, 2003.

[17] P. Serp and J. L. Figueiredo, Carbon Materials for Catalysis, Wiley, Hoboken, NJ, USA, 2009.

[18] A. E. Aksoylu, M. Madalena, A. Freitas, M. F. R. Pereira, and J. L. Figueiredo, "Effects of different activated carbon supports and support modifications on the properties of Pt/AC catalysts," Carbon, vol. 39, no. 2, pp. 175-185, 2001.

[19] K. Yasuda and Y. Nishimura, "The deposition of ultrafine platinum particles on carbon black by surface ion exchangeincrease in loading amount," Materials Chemistry and Physics, vol. 82, no. 3, pp. 921-928, 2003. 
[20] S. P. Jiang, "Issues on development of $(\mathrm{La}, \mathrm{Sr}) \mathrm{MnO}_{3}$ cathode for solid oxide fuel cells," Journal of Power Sources, vol. 124, no. 2, pp. 390-402, 2003.

[21] S. Imaizumi, K. Shimanoe, Y. Teraoka, N. Miura, and N. Yamazoe, "Preparation of carbon-supported perovskite-type oxides LaMn 1- ${ }_{y}, \mathrm{FeyO}_{3+\delta}$ based on reverse homogeneous precipitation method," Journal of the Electrochemical Society, vol. 151, no. 10, pp. A1559-A1564, 2004.

[22] I. Maurin, P. Barboux, Y. Lassailly, J. P. Boilot, F. Villain, and P. Dordor, "Charge-carrier localization on Mn surface sites in granular $\mathrm{LaMnO}_{3+\delta}$ samples," Journal of Solid State Chemistry, vol. 160, no. 1, pp. 123-133, 2001.

[23] A. Barnabé, M. Gaudon, C. Bernard, C. Laberty, and B. Durand, "Low temperature synthesis and structural characterization of over-stoichiometric $\mathrm{LaMnO}_{3+\delta}$ perovskites," Materials Research Bulletin, vol. 39, no. 4-5, pp. 725-735, 2004.

[24] S. Biniak, M. Walczyk, and G. S. Szymański, "Modified porous carbon materials as catalytic support for cathodic reduction of dioxygen," Fuel Processing Technology, vol. 79, no. 3, pp. 251-257, 2002.

[25] M. A. Montes-Morán, D. Suárez, J. A. Menéndez, and E. Fuente, "On the nature of basic sites on carbon surfaces: an overview," Carbon, vol. 42, no. 7, pp. 1219-1225, 2004.

[26] P. A. Gauden and M. Wiśniewski, " $\mathrm{CO}_{2}$ sorption on substituted carbon materials. Computational chemistry studies," Applied Surface Science, vol. 253, no. 13, pp. 5726-5731, 2007.

[27] Z. J. Sui, J. H. Zhou, Y. C. Dai, and W. K. Yuan, "Oxidative dehydrogenation of propane over catalysts based on carbon nanofibers," Catalysis Today, vol. 106, no. 1-4, pp. 90-94, 2005.

[28] D. B. Tagiyev, G. O. Gasimov, and M. I. Rustamov, "Carbon deposits on the surface of $\mathrm{CaO} / \mathrm{SiO}_{2}$ as active catalysts for the oxidative dehydrogenation of ethylbenzene," Catalysis Today, vol. 102-103, pp. 197-202, 2005.

[29] R. Klimkiewicz and E. B. Drag, "Catalytic activity of carbonaceous deposits in zeolite from halloysite in alcohol conversions," Journal of Physics and Chemistry of Solids, vol. 65, no. 2-3, pp. 459-464, 2004.

[30] J. P. Łukaszewicz, R. Wesołowski, and A. Arcimowicz, Patent application. Patent Office of Poland, No. P 384122, 2007.

[31] Standard DIN 66134, "Bestimmung der Porengrößenverteilung und der spezifischen Oberfläche mesoporöser Feststoffe durch Stickstoffsorption; Verfahren nach Barrett, Joyner und Halenda (BJH)," DIN Deutsches Institut fuer Normung, Berlin, Germany, 1998.

[32] Standard ISO 9277, "Determination of the Specific Surface Area of Solids by Gas Adsorption Using the BET Method," International Organization for Standardization, Geneva, Switzerland, 1995.

[33] G. Horvath and K. Kawazoe, "Method for the calculation of effective pore size distribution molecular sieve carbon," Journal of Chemical Engineering of Japan, vol. 16, no. 6, pp. 470-475, 1983.

[34] N. A. Seaton, J. P. R. B. Walton, and N. quirke, "A new analysis method for the determination of the pore size distribution of porous carbons from nitrogen adsorption measurements," Carbon, vol. 27, no. 6, pp. 853-861, 1989.

[35] Operator's manual, "Micromeritics ASAP 2010 accelerated surface area and porosimetry system," Norcross, Micromeritics Instrument Corporation, 1995.

[36] B. Buczek, "Characterization of carbon molecular sieves based on nitrogen and carbon dioxide adsorption," Chemical and Process Engineering, vol. 31, no. 2, pp. 217-224, 2010.
[37] D. Lozano-Castelló, D. Cazorla-Amorós, and A. LinaresSolano, "Usefulness of $\mathrm{CO}_{2}$ adsorption at $273 \mathrm{~K}$ for the characterization of porous carbons," Carbon, vol. 42, no. 7, pp. 12311236,2004

[38] J. Jagiello and M. Thommes, "Comparison of DFT characterization methods based on $\mathrm{N}_{2}, \mathrm{Ar}, \mathrm{CO}_{2}$, and $\mathrm{H}_{2}$ adsorption applied to carbons with various pore size distributions," Carbon, vol. 42, no. 7, pp. 1225-1229, 2004.

[39] S. Furmaniak, A. P. Terzyk, P. A. Gauden, P. J. F. Harris, and P. Kowalczyk, "Can carbon surface oxidation shift the pore size distribution curve calculated from $\mathrm{Ar}, \mathrm{N}_{2}$ and $\mathrm{CO}_{2}$ adsorption isotherms? Simulation results for a realistic carbon model," Journal of Physics Condensed Matter, vol. 21, no. 31, Article ID 315005, 2009.

[40] S. Furmaniak, A. P. Terzyk, P. A. Gauden, P. J. F. Harris, and P. Kowalczyk, "The influence of carbon surface oxygen groups on Dubinin-Astakhov equation parameters calculated from $\mathrm{CO}_{2}$ adsorption isotherm," Journal of Physics Condensed Matter, vol. 22, no. 8, Article ID 085003, 2010.

[41] A. P. Terzyk, S. Furmaniak, P. A. Gauden, P. J. F. Harris, J. Włoch, and P. Kowalczyk, "Hyper-parallel tempering Monte Carlo simulations of Ar adsorption in new models of microporous non-graphitizing activated carbon: effect of microporosity," Journal of Physics Condensed Matter, vol. 19, no. 40, Article ID 406208, 2007.

[42] C. R. Reid and K. M. Thomas, "Adsorption of gases on a carbon molecular sieve used for air separation: linear adsorptives as probes for kinetic selectivity," Langmuir, vol. 15, no. 9, pp. 32063218, 1999.

[43] K. S. W. Sing and R. T. Williams, "The use of molecular probes for the characterization of nanoporous adsorbents," Particle and Particle Systems Characterization, vol. 21, no. 2, pp. 71-79, 2004.

[44] W. A. Steele, "The physical interaction of gases with crystalline solids. I. Gas-solid energies and properties of isolated adsorbed atoms," Surface Science, vol. 36, no. 1, pp. 317-352, 1973.

[45] G. K. Step and M. V. Petrovichev, "Pressure swing adsorption for air separation and purification," Chemical and Petroleum Engineering, vol. 38, no. 3-4, pp. 154-158, 2002.

[46] C. R. Reid, I. P. O’koye, and K. M. Thomas, "Spherical adsorptives as probes for kinetic selectivity," Langmuir, vol. 14, no. 9, pp. 2415-2425, 1998.

[47] J. P. Łukaszewicz, S. Imaizumi, M. Yuasa, K. Shimanoe, and N. Yamazoe, "New approach towards preparation of efficient gas diffusion-type oxygen reduction electrode," Journal of Materials Science, vol. 41, no. 19, pp. 6215-6220, 2006.

[48] S. F. Miralaï, R. Avni, E. Francke, D. Morvan, J. Amouroux, and $\mathrm{H}$. Nickel, " $\mathrm{LaMnO}_{3}$ perovskite thin film deposition, from aqueous nitrate solutions of $\mathrm{La}$ and $\mathrm{Mn}$, in a low-pressure plasma expanded through a nozzle (PETN)," Thin Solid Films, vol. 303, no. 1-2, pp. 17-26, 1997.

[49] A. Cyganiuk, R. Klimkiewicz, A. Olejniczak, and J. P. Łukaszewicz, "Biotechnological fabrication of $\mathrm{LaMnO}_{3}$ carbon catalyst for n-butanol conversion to ketones," Carbon, vol. 48, no. 1, pp. 99-106, 2010. 

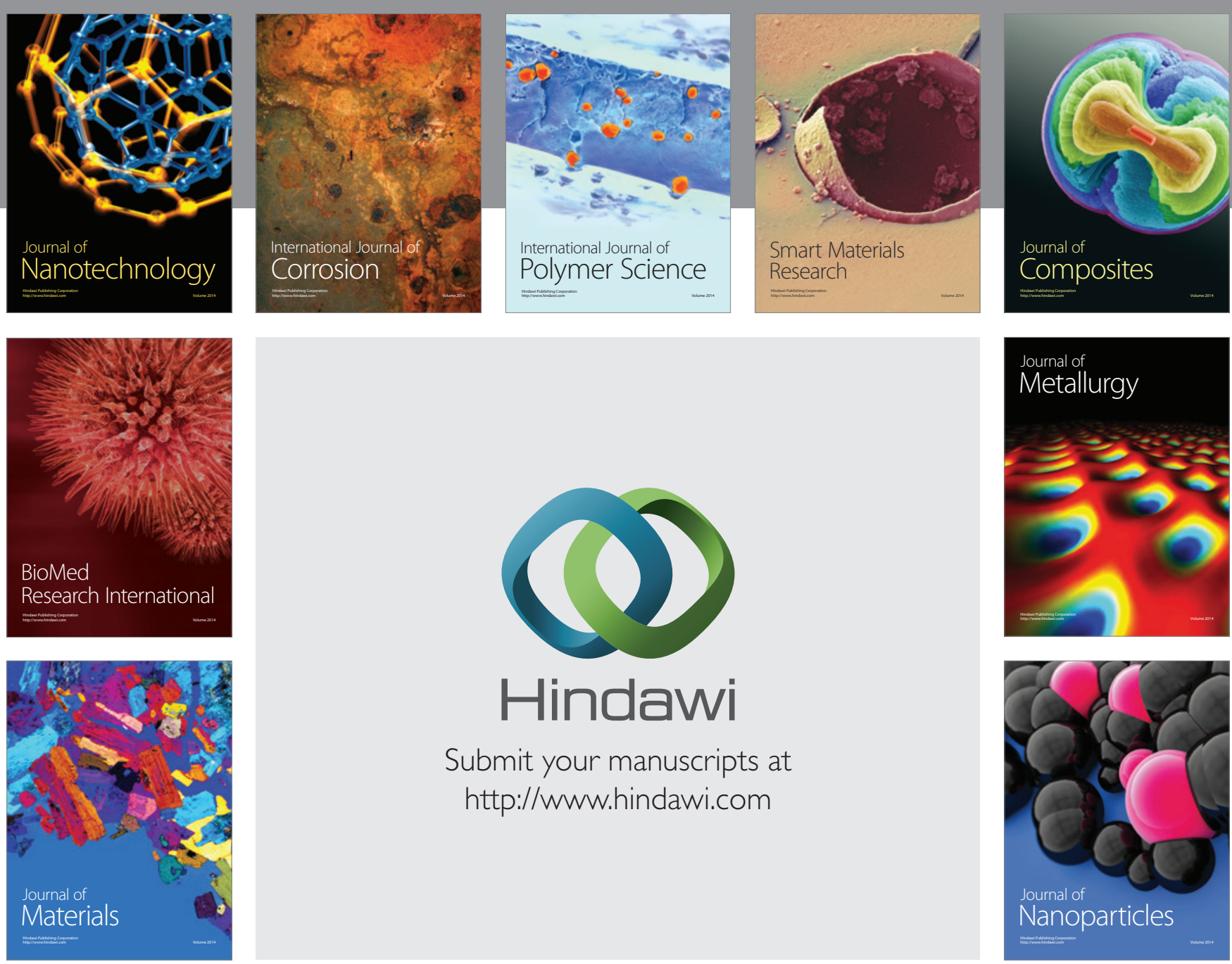

Submit your manuscripts at http://www.hindawi.com
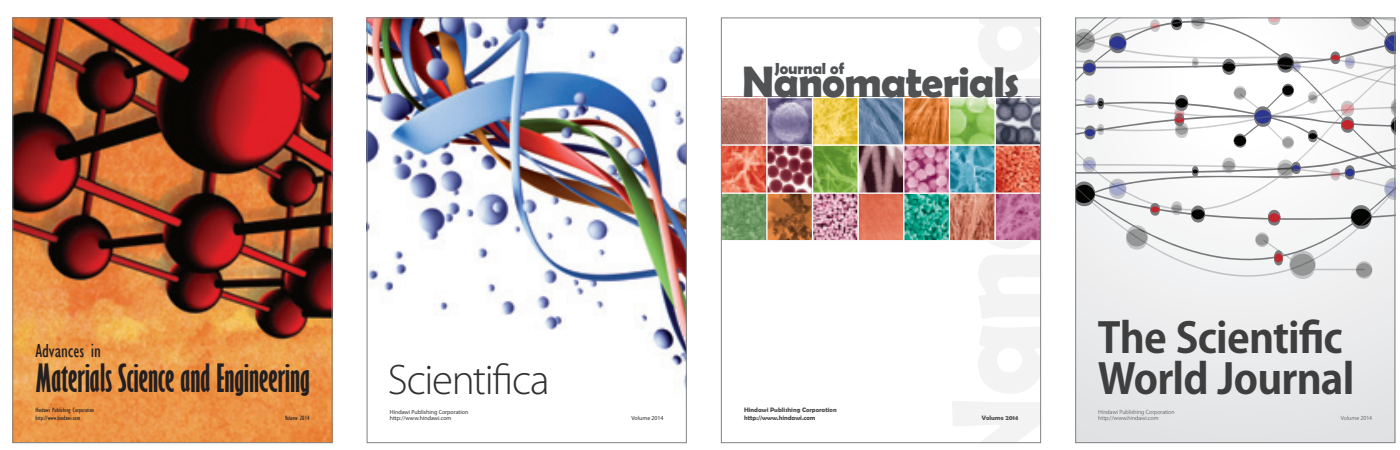

\section{The Scientific World Journal}
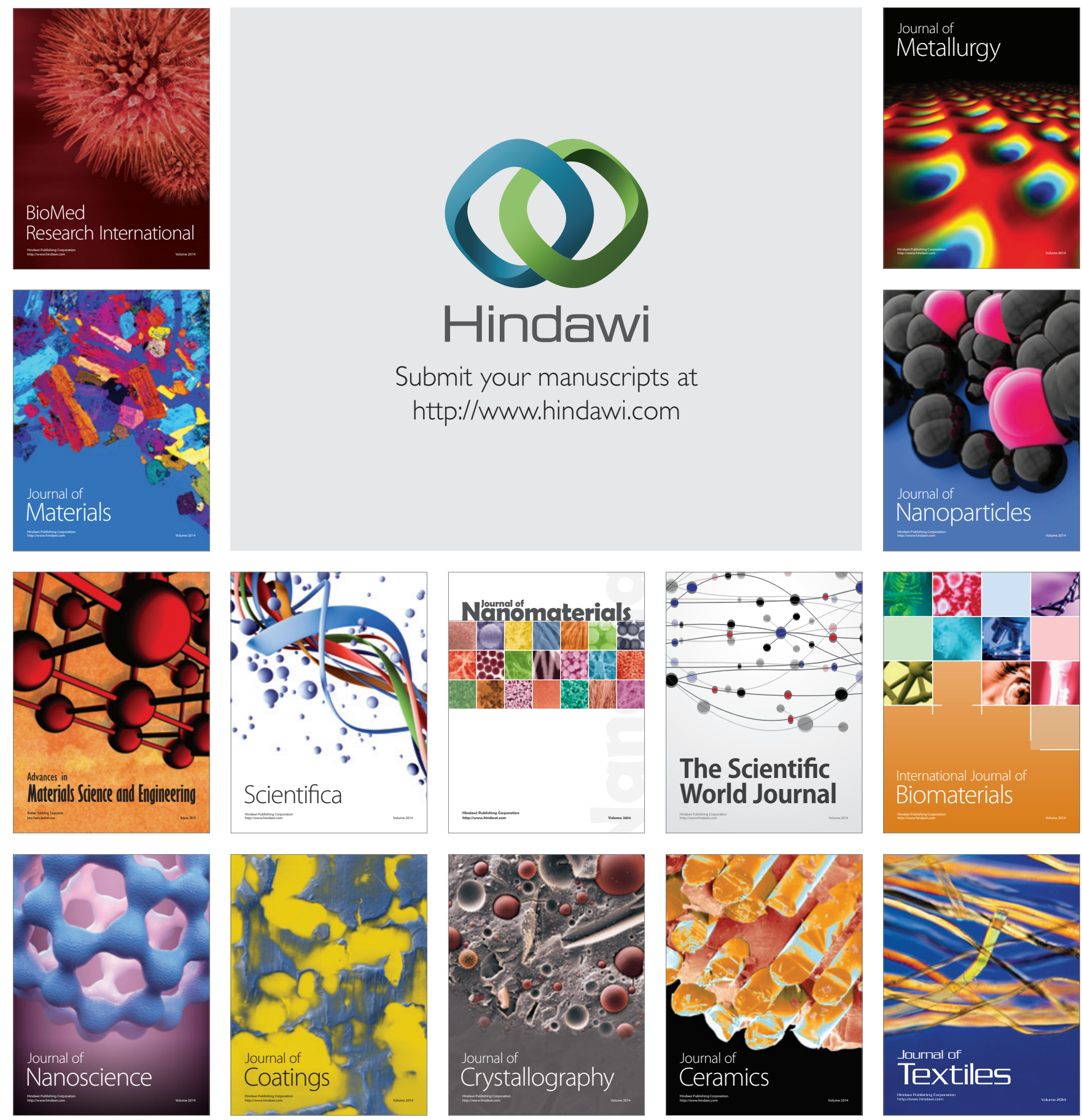